\title{
MANAGEMENT OF ELECTRONIC AND ELECTRICAL EQUIPMENT WASTE COLLECTION IN MUNICIPALITIES
}

\author{
Sergey Filin ${ }^{1,}$, Irina Kalinina ${ }^{1}$, Vladimir Maslennikov ${ }^{1}$, Saltanat Ibraimova $^{2}$, Vladimir Velikorossov $^{1}$, and Alexey \\ Chaikovsky $^{1}$ \\ ${ }^{1}$ Plekhanov Russian University of Economics, Department of Management, 117997, Stremyanny Lane, 36, Moscow, Russian Federation \\ ${ }^{2}$ M.Auezov South-Kazakhstan State University, 160012, Tauke Khan Ave, Shymkent, Kazakhstan
}

\begin{abstract}
The article considers the justification of the possibility of organizing a waste management system of electronic and electrical equipment dangerous to human health and the environment and the subsequent use of secondary raw materials based on them. The current state of production sector of collection and disposal of waste of electronic and electrical equipment in the EU and Russia was analyzed. A scheme for the organization of a waste management system for electronic and electrical equipment, including the main methods of organization and stages of the cycle of collection and processing of waste in municipalities, forms of organization of work with the population, a formula for calculating the need for the number of necessary vehicles for mobile reception points, has been proposed. It was concluded that at present there is a real opportunity for the implementation in municipalities of a project to create an organization of a waste management system for electronic and electrical equipment, which does not require significant funds from the municipal budget.
\end{abstract}

\section{Introduction}

Technological progress, primarily digitalization [1], rising living standards of the population lead to an increase in the consumption of electronic and electrical equipment throughout the world and, as a result, an increase in waste of electronic and electrical equipment. According to the UN Environment Program, up to 50 million tons of waste of electronic and electrical equipment are generated annually in the world, and about 1.5 million tons in Russia, of which about $7 \%$ are processed. Currently, the population receives waste of electronic and electrical equipment as part of marketing campaigns and programs for the exchange of old equipment when selling a new one conducted by large network retailers. Part of the household appliances comes to processors from service centers of large manufacturers, including for the extraction of liquid materials from them (ferrous and non-ferrous metals, printed circuit boards). At the same time, few Russian enterprises sort and process waste of electronic and electrical equipment, mainly from legal persons, using modern technologies. Individual promotions and the current regime of processing waste of electronic and electrical equipment in Russia are not able to ensure an even load of existing processing facilities. As a result, the level of collection and processing of waste of electronic and electrical equipment is lower than in the EU countries. As a result, a large amount of waste from electronic and electrical equipment, containing both hazardous substances and valuable secondary materials, is not involved in processing and subsequent use, but usually ends up in illegal landfills.

Analysis shows that substances of hazard class I (mercury, lead, beryllium and its compounds, cadmium and its compounds, hexavalent chromium, arsenic) may be present in the composition of this type of waste. Some types of freons (primarily chlorosubstituted) used in refrigeration and climatic equipment are ozone-depleting [2]. As a result of natural processes of decay or ignition of materials with these substances in landfills, their release into the environment can occur. Insufficient attention to the problem of electronic and electrical equipment waste management entails serious negative consequences: diseases of people due to environmental degradation associated with pollution of water, soil and air with waste of electronic and electrical equipment.

Although the adoption of Federal Law No. 12.29.2014 of 458-FL "On Amendments to the Federal Law "On Production Waste and Consumption" created certain conditions for ensuring environmentally safe processing of waste, including electronic and electrical equipment, the lack of necessary statistical data on the volumes of electronic and electrical equipment waste and their processing is still a big problem in Russia. The decision of the Government of the Russian Federation established a moratorium on the introduction of environmental fees for electronic and electrical goods since 01.01.2019. As a result, the financial participation of producers or importers in the disposal of goods after the end of their life cycle has become essentially voluntary. Also before the present there are no

* Corresponding author: Filin.SA@rea.ru 
requirements concerning the licensing of a number of types of activity provided by law No. 458-FL on waste management of electronic and electrical equipment, normative documents of realization of responsibility by producers and some other provisions of this law.

\section{Methodology}

To solve the above-mentioned problems, it is necessary to establish an effective system for managing waste collection of electronic and electrical equipment based on the principles of project management, taking into account legal, administrative, environmental, medical and technological aspects, as well as the specifics of the production sector in Russia, within the framework of the system-information approach methodology. Analysis of foreign and Russian practice of waste management of electronic and electrical equipment makes it possible to identify the following main methods of organization of the waste management system of electronic and electrical equipment in municipalities.

1. Organization of mobile collection points.

2. Retail facilities (especially large network ones) are natural collection points for any type of equipment due to the popularity of Recycling promotions. To launch the collection of equipment on an ongoing basis, an agreement is needed between manufacturers and retail on the possibility of its acceptance during the period of model calculation, while maintaining attractive promotional conditions for citizens as a motivating factor for the delivery of waste electronic and electrical equipment. The option of collecting packaging, glass and plastic at retail facilities, which is a non-core load on retail in the absence of motivation of citizens to hand over these types of waste, is possible as part of the accumulation of their own waste by retail and the corresponding amendments to Federal Law No. 89-FL "On Production and Consumption Waste".

Financing of promotions that increase sales, eliminate illiquid stocks of electronic and electrical equipment, conduct an advertising campaign, affect the target audience (potential consumers), according to the established practice is carried out by the manufacturer/importer. If the area/container is provided to the population without promotions, the household appliances owner turns to the seller, pays for the costs of transporting the equipment to special collection places or for processing production. For this procedure, it is necessary to agree on obligations between the manufacturer, retail and recycler on mutually beneficial terms.

3. Use of the method of organization of stationary points for receiving waste of electronic and electrical equipment in the territory of the municipality, which allows to solve problems: 1) territorial accessibility for users; 2) the regularity of waste reception regardless of the volume of container filling, which is a limitation in the case of large chain retailers. The establishment of such points requires taking into account the following conditions: a) electronics and household appliances can be, therefore, it is necessary to ensure the safety of the collected waste (reliable security and alarm systems) and the safety of its collection to prevent violations of the hull (to maintain the "attractiveness of electronic and electrical equipment for a certain part of the population" and the release of pollutants into the environment; $b$ ) the location of the point should be in a place of transport accessibility with the possibility of entrance to it by a vehicle with a sufficient load capacity and body volume of at least $20 \mathrm{~m}^{3}$; c) selection and allocation of the corresponding land plot with connected communications.

4. Using the method of organizing collection points on the basis of service centers, when the customer refuses to pick up the failed and unserviceable electronic and electrical equipment of the service center, and this equipment is returned to manufacturers. The peculiarities of the organization of such points: a) their small area makes it difficult to store electronic and electrical equipment intended for recycling, which requires the prompt removal of the agreed amount of waste of the latter; b) many of these centres are currently withdrawing the most valuable components for subsequent implementation by secondary resource organizations.

The type of study is reproducing studies, the subject of which is a repetition of previous studies based on the method of organizing mobile waste collection points to assess the possibility of its use for collecting electronic and electrical equipment from the population of a municipality.

\section{Results and Discussion}

As the main form of collection of waste of electronic and electrical equipment from the population, at the first stage of the creation of electronic and electrical equipment waste collection management system, it is proposed to use the method of organizing mobile collection points. It is proposed to place the main mobile collection points at agreed addresses in municipalities. In order to expand the network of mobile collection points, it is advisable to explore the possibility of short-term placement of additional mobile collection points in residential areas, for example, in accessible proximity to educational institutions with well-known addresses. Comprehensive mobile collection points should be located in isolation from residential buildings, children's and medical institutions, outside the parking places of transport in places where access roads can be arranged, on the basis of the development and coordination of predesign ones in accordance with the established procedure (permitting documentation, etc.) and design materials and in accordance with Sanitary rules and norms 2.2.1/2.1.1.1200-03 "Sanitary protection zones and sanitary classification of enterprises, structures and other facilities" [3-12].

To study the demand and conditions for the organization of the reception of waste of electronic and electrical equipment, the number of flights $(\mathrm{N})$ of vehicles for one year in a certain territory was calculated for the method of organizing mobile collection points according to the formula: 


$$
N=\left(\frac{Q}{f} \bullet \frac{t}{365}\right) n, \quad \text { at } \quad Q \leq M
$$

where Q is the average amount of collected waste of electronic and electrical equipment in a certain territory for the period $\mathrm{t}$, tons; $\mathrm{M}$ is loading of existing processing facilities for this territory for the period $t$, tons; $t$ is the average number of days that ensure uniform loading of the existing processing capacity $\mathrm{M}$ with collected waste of electronic and electrical equipment for a given territory; $\mathrm{f}$ is average minimum required filling capacity of electronic and electrical equipment of the vehicle collected by wastes, not exceeding its carrying capacity, $\mathrm{t} ; \mathrm{n}$ is the number of periods $\mathrm{t}$ for 1 year, where $\mathrm{n}=$ $365 / \mathrm{t}$.

Hence, the number of $\mathrm{L}$ vehicles required for one year will be:

$$
L=\frac{N}{k} \quad, \quad \text { at } \quad k \leq 1,
$$

where $\mathrm{k}$ is a factor that takes into account possible breakdowns of the vehicle or absenteeism of its maintenance personnel for one year and, as a result, its replacement by reserve transport.

Hence, the number of necessary mobile collection points will be:

$$
P C P=\frac{N}{n} \text {. }
$$

The most important condition for the effective organization of the electronic and electrical equipment waste collection management system is to ensure the standards of their guaranteed processing in a safe way. For their development, it is necessary to determine [13]: 1) the scale of activities and what stages of the life cycle of electronic and electrical equipment need to be included in the electronic and electrical equipment waste collection management system; 2) the procedure for the organization of collection and storage of waste of electronic and electrical equipment and the requirements governing these operations; 3) transportation of electronic and electrical equipment wastes in a safe way; 4) technologies for introducing reuse or sending for modernization of collected waste. In the distribution of functions in the electronic and electrical equipment waste collection management system for integrated disposal, the most important participants are manufacturers, local authorities and processors (figure 1).

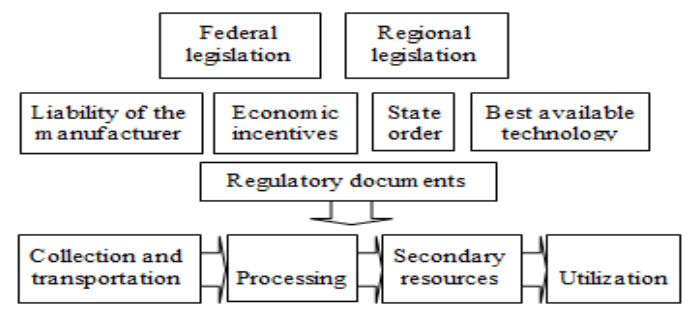

Fig. 1. Integrated Disposal System [14].
In the EU, producer responsibility for the full life cycle of products [15] may be individual (specific producer for product) and extended (collective), where producers (or industry) are responsible for the disposal of certain groups of goods after the end of their life cycle.

As foreign practice has shown, increased responsibility is one of the most important ways to facilitate the collection and environmentally sound recycling of electronic and electrical equipment waste. As a rule, this process is implemented through collective systems. In most EU countries, such systems are nonprofit organizations involved in the organization of waste collection of electronic and electrical equipment, including informing the public about the need for separate collection. Organizations can be created both by individual producing or importing companies and by associations of companies. Collective systems for the realization of responsibility allow manufacturers to optimize their costs for the collection and disposal of products through strict control over the use of these funds. As a rule, payments by companies to liability systems are significantly lower than the environmental or recycling fees levied by the state.

Although Law No. 458-FL provides for producers to exercise their responsibilities both individually and through collective organizations, the necessary regulations have not yet been adopted. In case of individual liability in Russia, the manufacturer (supplier) is charged when their products appear on the market [14].

To organize the export of large-sized equipment at the request of residents of the municipality by a consortium of manufacturers or a licensed collecting company, it is advisable to organize a centralized dispatch service.

Effective control of costs for collection, processing and disposal of waste of electronic and electrical equipment for the municipality is ensured by: 1) transparency of costs for all participants and justification of price increase for the end user; 2) the possibility of tracking unscrupulous participants of this control scheme; 3) prevention of competition between producers on these expenses. The layout of the electronic and electrical equipment waste management system is shown in Figure 2.

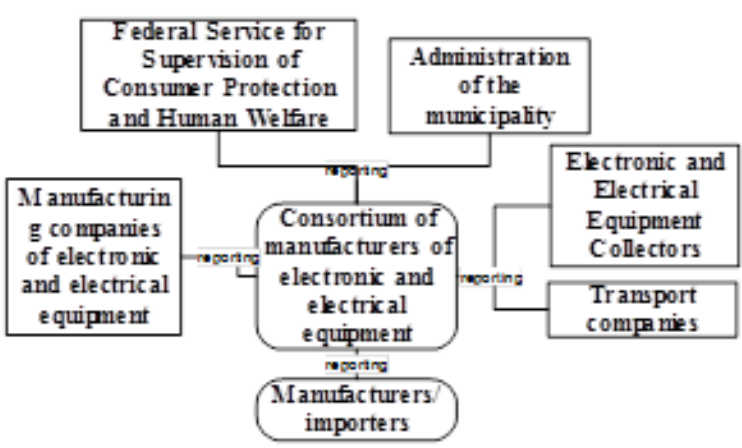

Fig. 2. Layout of electronic and electrical equipment waste management system. 
The department responsible for environmental management and environmental protection in the relevant municipality regulates the coordination of collection and processing: establishes control indicators and waste collection points of electronic and electrical equipment for subordinate territorial entities, issues the necessary permits for collection and processing, monitors the collection places and compliance of carriers and processors with the requirements of documents regulating the waste management of electronic and electrical equipment.

Manufacturers of electronic and electrical equipment finance the costs of organizing a electronic and electrical equipment waste collection and processing management system (including the process of economic use of electronic and electrical equipment) through the "collection for disposal", which they transfer to the waste disposal fund, provide information on the volume of goods released to the market. The Consortium of Manufacturers of Electronic and Electrical Equipment, which is controlled by competent government agencies, helps entrepreneurs to comply with the requirements of regulations on the collection and processing of waste of electronic and electrical equipment, and implements and coordinates a system of their separate collection, processing and reuse. Consumers deliver already used electronic and electrical equipment to its collection points, operators of economic use of waste of electronic and electrical equipment deliver them from collection point store cycling enterprises.

Waste collection companies for electronic and electrical equipment coordinate and finance their collection, transportation and correct disposal, determine, control, pay and sign the necessary documents on the use of waste collection sites for electronic and electrical equipment, carriers and processors. Carrier companies ensure the delivery of electronic and electrical equipment waste from collection points to processing enterprises that dispose of and recycle it. The task of the consortium of processors is to carry out, based on regulatory acts, the economic use of electronic and electrical equipment and ensure separate collection and processing of waste.

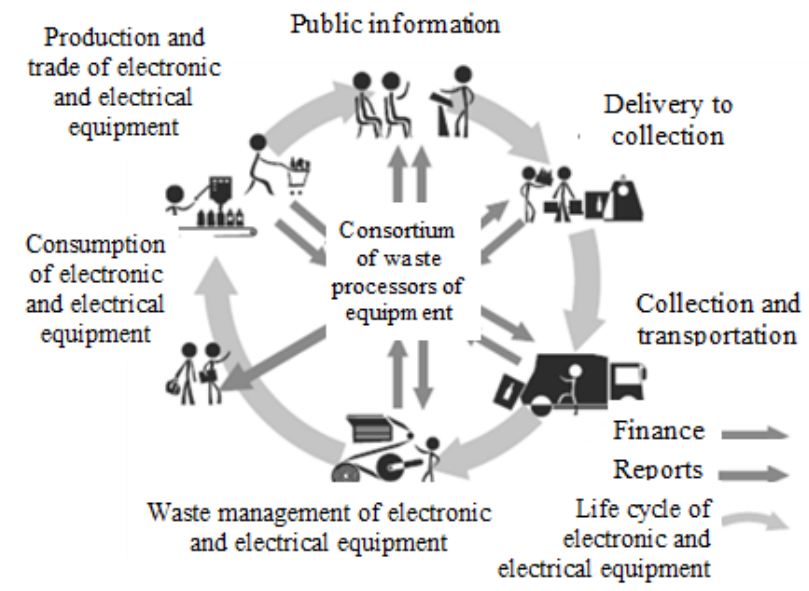

Fig. 3. Electronic and household waste collection and processing cycle.
Part of the waste of electronic and electrical equipment currently, bypassing collection points and processing companies, is in the flow of solid household waste. Management companies and operators responsible for the removal of solid household waste can assist in the recovery of electronic and electrical equipment from the latter and transfer them to licensed collectors, for which it is necessary to develop a mechanism for mutually beneficial interaction between them and processors [14].

Thus, the electronic and electrical equipment waste management system should include: 1) legal and regulatory framework; 2) organization: a) financial control, b) information exchange and reporting, c) management processes, d) operating activities; 3) appropriate infrastructure. The main participants in the organization and development of the electronic and electrical equipment waste collection management system are presented in Table 1.

Table 1. Main participants in the organization and development of the electronic and electrical equipment waste collection management system [14].

\begin{tabular}{|c|c|c|}
\hline No. & $\begin{array}{l}\text { Institutional } \\
\text { element }\end{array}$ & Distribution of responsibility \\
\hline 1 & $\begin{array}{l}\text { Administration } \\
\text { of the } \\
\text { municipality }\end{array}$ & $\begin{array}{l}\text { Legislative framework } \\
\text { Licensing } \\
\text { Plan Confirmation } \\
\text { Monitoring compliance with the } \\
\text { law }\end{array}$ \\
\hline 2 & Manufacturers & $\begin{array}{l}\text { Establishment and financing of } \\
\text { non-commercial schemes, } \\
\text { including: organization of } \\
\text { specialized infrastructure, } \\
\text { contracting companies for the } \\
\text { collection and processing of } \\
\text { waste of electronic and electrical } \\
\text { equipment }\end{array}$ \\
\hline 3 & Distribution & $\begin{array}{l}\text { Designated area for collection } \\
\text { points } \\
\text { Obligation to accept waste of } \\
\text { electronic and electrical } \\
\text { equipment free of charge }\end{array}$ \\
\hline 4 & Operators & $\begin{array}{l}\text { Provide environmentally friendly } \\
\text { recycling }\end{array}$ \\
\hline
\end{tabular}

An important role in the electronic and electrical equipment waste management system belongs to the consortium of manufacturers of electronic and electrical equipment, which forms and regulates the system of responsibility of manufacturers for the processing and disposal of waste of electronic and electrical equipment.

One of the main indicators determining the effectiveness of the electronic and electrical equipment waste management system is the degree of utilization of the latter. In order to increase the level of recycling of electronic and electrical equipment waste, additional measures are needed to increase the use of waste recovered from waste. When preparing a project to create a electronic and electrical equipment waste management system, it is advisable to study the possibility of using secondary materials extracted from waste, for example plastics, for the manufacture of goods necessary in the economy of municipalities, and to develop proposals aimed at stimulating enterprises producing products from these secondary materials. 
The application of all possible legal forms of electronic and electrical equipment household waste collection of in $\mathrm{s}$ requires carefully designed and organized advertising and propaganda work with the population, aimed at informing them about the time and place of receipt of waste, explaining and stimulating the population about the need to collect waste of electronic and electrical equipment separately from other types of waste. The administration of municipalities has a supervising role in working with the population, and this work should be entrusted to the management companies responsible for the removal of solid household waste, and a consortium of manufacturers of electronic and electrical equipment, which finances public information projects.

Possible forms of organization of work with the population: 1) creation of a specialized site, Promoting a separate collection of waste of electronic and electrical equipment, containing information on stationary collection points, places and dates of operation of mobile collection points, schedule of removal of certain types of waste of electronic and electrical equipment, for example, information and communication technologies, entertainment electronics and refrigeration equipment, household appliances, electrical tools and electronic toys, lamps and lamps, chemical current sources, etc.; 2) placement of information on the electronic and electrical equipment waste collection control system; 3) organization of a series of broadcasts, reports and publications of materials in the media supervised by the municipality on the problem of collecting and environmentally safe disposal of waste of electronic and electrical equipment; 4) holding in parks lectures, competitions, concerts, etc., with school students and students - seminars, master classes, competitions related to the collection of waste electronic and electrical equipment, during which specialized films can be shown, well-known athletes, actors, politicians; c) individual work with the population of volunteers, representatives of public environmental organizations, students of specialized departments and faculties of universities, etc.

\section{Conclusions}

Currently, there is a real opportunity for the implementation in municipalities of projects to organize and develop the functioning of the electronic and electrical equipment waste management system, which does not require significant funds from the municipal budget, ensuring the environmentally safe and costeffective management of these waste, reducing the environmental load and improving the environment in the relevant municipalities. The implementation of such projects is of particular importance in connection with the development of regulatory documentation for the implementation of laws No. 89-FL and No. 458-FL, which requires practical development of methods for the implementation of these laws and obtaining an objective assessment of the possibilities of collecting and processing waste of electronic and electrical equipment.

\section{References}

1. V.V. Velikorossov, A.V. Rechinskiy, L.V. Chernenkaya, S.A. Filin, A.V. Chernenkii, Digital Economy as a Tool for Reducing of Uncertainty in Strategic Managerial Decisions, Proceedings CSIS'19 Eleventh International Scientific and Theoretical Conference "Communicative strategies of Information Society" (2019)

2. S.A. Filin, V.E. Rogalin, I.A. Kaplunov, Russian Journal of Applied Chemistry, 91, 10 (2018)

3. J.P. Souza, P.E. Freitas, L.D. Almeida, M.G. Rosmaninho, Waste Management, 65 (2017)

4. J.-B. Bahers, J. Kim, Resources, Conservation and Recycling, 129 (2018)

5. C. Duan, J. Han, S. Zhao, Z. Gao, J. Qiao, G. Yan, Waste Management, 77 (2018)

6. R.M. Grigorescu, M.E. Grigore, L Iancu, P. Ghioca, R.-M. Ion, Recycling, 4, 3 (2019)

7. S. Hammani, A. Barhoum, S. Nagarajan, M. Bechelany, Materials, 12, 19 (2019)

8. M.L. Rockhold, J.L. Robinson, K. Parajuli, X. Song, Z.F. Zhang, T.C. Johnson, Hydrogeology Journal (2020)

9. G. Chauhan, P.R. Jadhao, K.K. Pant, K.D.P. Nigam, Journal of Environmental Chemical Engineering, 6, 1 (2018)

10. E. Bottani, R. Montanari, M. Rinaldi, International Journal of Simulation and Process Modelling, 14, 3 (2019)

11. H. Ismail, M.M. Hanafiah, Journal of Cleaner Production, 238 (2019)

12. S.K. Ghosh, R. Baidya, D. De, B. Debnath, J. Li, L. Zheng, A.K. Awasthi, M.A. Liubarskaia, J.S. Ogola, A.N. Tavares, Waste Management \& Research, 34, 8 (2016)

13. V.V. Maslennikov, F. de Melo, E.V. Popova, et all, Asian Social Science, 11, 20 (2015)

14. I.A. Kalinina, V.V. Maslennikov, S.A. Filin, Ecology of industrial production, 13 (2018)

15. V.A. Komissarov, International Conference "Organization of management of waste electronic and electrical equipment in Russia: the situation in the industry and its prospects" [Electronic resource], UNIDO PROJECT US/RUS/09/001 Available at: http://www.umweltbundesamt.de/sites/default/file s/international_conference_booklet.pdf 